\title{
POTENTIAL AMELORATIVE EFFECT OF PANAX GINSENG ON HEPA- TORENAL DAMAGE OCUURED IN HYDROXUREA-TREATED RATS
}

\author{
Samar S. Elblehi*, Dina R. S. Gad El-Karim \\ Department of Pathology and Clinical Pathology, Faculty of Veterinary Medicine, Alexandria \\ University, 11511, Egypt
}

*Corresponding author, E-mail: samarsaad30@yahoo.com

\begin{abstract}
Hydroxyurea $(\mathrm{HU})$ is an anti-neoplastic drug which is used for treatment of many types of tumors; however, its wide range of deleterious effects may limit its medical usage. This study was conducted to assess the possible protective role of Panax ginseng extract (Ginseng) against $\mathrm{HU}$ - induced hepato-renal damage in rats. Forty male Wistar albino rats were randomly divided into four equal groups (10 rats each). Group I (control) received $1 \mathrm{ml}$ purified water. Group II (Ginseng-treated) received $200 \mathrm{mg} / \mathrm{kg}$ body weight (b.wt) of Panax ginseng extract. Group III (HU-treated) received HU at a dose of $500 \mathrm{mg} /$ kg b.wt. Group IV (HU plus ginseng) received HU and Panax ginseng extract in similar doses of group II and III. All the treatments were administrated orally. Treatment with Panax ginseng failed to ameliorate the hematological alterations caused by $\mathrm{HU}$, but, its ability to alleviate hepato-renal cytotoxic effect was proved through significant reduction in plasma level of hepato-renal injury biomarkers (AST, ALT, GGT, urea and creatinine) which were elevated in HU-treated group. Also, this effect was affirmed by decreased level of plasma pro-inflammatory cytokines (TNF- $\alpha$ and IL-6) and enhanced anti-oxidant state (decreased MDA content and increased GPX activity) of hepato-renal tissues upon Panax ginseng extract administration with HU. Histopathologically, HU induced impairments in both hepatic and renal tissues of the treated rats. Conversely, concurrent administration of ginseng with $\mathrm{HU}$ partially improved these alterations.
\end{abstract}

Key words: hydroxyurea; hepato-renal toxicity; Panax ginseng; rats

\section{Introduction}

Hydroxyurea (HU) as an anti-neoplastic drug is used in humans and dogs for the treatment of chronic myelogenous leukemia, polycythemia, ovarian cancer, melanoma, and squamous cell carcinoma of the head and neck. Also, it has been used for treatment of renal cell carcinoma, transitional carcinoma of the urinary bladder, prostatic carcinoma, and carci- noma of the uterine cervix in addition to thrombocytosis (1). Moreover, HU has been used for treatment of mast cell tumor and hypereosinophilic syndrome in dogs $(2,3)$. It is the only approved option to be used in humans with sicklecell disease as it reduces vaso-occlusive crises frequency, blood transfusions, the number of days spent in hospital and mortality of these patients (4). That's because administration of $\mathrm{HU}$ to sickle-cell disease patients increases the production of erythrocytes fetal hemoglobin which 
can carry more oxygen than adult hemoglobin (5), decreases circulating neutrophils, enhances the deformability of erythrocytes, decrease adhesion of erythrocytes to endothelium, promotes vasodilation through production of nitric oxide and increasing adenosine deaminase activity in circulating monocytes leading to lower adenosine levels $(6,7)$. The mechanism of action of $\mathrm{HU}$ as an anti-neoplastic drug depends on its ability to arrest rapidly dividing cells at $S$ phase of cell division (8) through inhibition of the class I ribonucleotidereductase enzyme (9) which is responsible for the formation of deoxyribonucleotides from ribonucleotides (10) by inactivating the tyrosyl radical required for enzyme activity leading to massive reduction in the production of deoxyribonucleotides that are necessary for DNA replication $(11,12)$.

$\mathrm{HU}$ is generally tolerated however it has a low safety margin due to myelosuppression, as the earliest and most common reported adverse findings in human patients were pan-leukopenia, anemia and thrombocytopenia $(3,5,13)$. Additionally, growth retardation spermatogenic arrest, hematopoietic, lymphoid, cardiovascular, and gastrointestinal toxicity associated with hemosiderosis of spleen and liver have been observed in dog toxicity studies $(13,14)$. In rats administration of $\mathrm{HU}$ at high doses induced reduction in the body weight gain, anemia, leukocytopenia, thrompocytopenia associated with hypocellularity of lymphoid organs and bone marrow; epithelial degeneration and/or dysplasia of the stomach and small intestine (14) and decreased fertility in males as itinduced testicular atrophy and decreased sperm production (15), also, it can induce hepatic damage with fatty changes (13). Cardiovascular effects and slight methemoglobinemia were detected in some species " at doses higher than clinical levels" $(13,16)$, skin and nail lesions have been reported in human and canine patients $(2,17,18)$. In addition, HU can induce lung toxicity with pulmonary edema, lung infiltration and dyspnea (19), and pulmonary fibrosis in a minority of patients (20).

Traditional herbal medicine has become the point of attraction in the clinical and experi- mental research. Panax ginseng (Korean ginseng), commonly known as ginseng is a famous medicinal plant that has been used extensively in traditional Chinese medicine for more than 2,000 years (21-24). Bioactive constituents of ginseng include ginsenosides, polysaccharides, phenolics, flavonoids, and polyacetylenes (25). In particular, the main active components of ginseng are the ginsenosides (or triterpenoidsaponins), aswell as about 38 more types of ginsenosides have been identified approximately (26). These compounds are proved to be responsible for most of the favorable effects of ginseng, which has a wide range of protective or therapeutic effects against many diseases. Ginsenosides have been studied intensively as the main active components of ginseng that have a variety of pharmacological effects, including anti-diabetes (27), anti-oxidant and anti-inflammatory (28), anti-aging (29), antiobesity (30), immune modulator and anti-tumor effect $(31,32)$. To the pest of our knowledge, very few detailed reports of HU induced toxicity in lab animals have been published and the published reports were insufficient to demonstrate the hepato-renal effect of HU administration. In this context, this study was conducted to assess the adverse effects of HU administration to male albino rats up to 1 month and the ability of Panax ginseng to ameliorate these effects.

\section{Materials and methods}

\section{Chemicals}

Commercially available formulation of hydroxyurea capsules (Hydrea ${ }^{\circledR} 500 \mathrm{mg}$, E R Squibb \& Sons Ltd., England) was used. Panax ginseng extract were obtained in form of capsules containing $550 \mathrm{mg}$ of Korean red ginseng extract, $8 \%$ ginsenosides (Nature's Way, USA).

\section{Animals and experimental design:}

Forty male Wistar albino rats, 6-8 weeks old and 180-200 g body weight were obtained from the closed bred colony in Faculty of Agriculture, Alexandria University, Egypt. Rats were housed in metal cages under controlled environmental conditions $\left(24-27{ }^{\circ} \mathrm{C}\right.$ temperature, $55 \% \mathrm{RH}$, and $12 \mathrm{~h}$ light/dark cycle) for 2 weeks. 
They were observed carefully during this period to make sure that they were free from any apparent health problem. All animals fed on a standard laboratory diet and received water $a d$ libitum during the experiment. This study was approved by committee of Care and Use of Laboratory Animals of Alexandria University.

After the acclimatization period, rats were allocated into four groups (10/each). All groups received daily oral intubation using stomach tube and the treatment lasted for 30 days as the following: Group I (control) received $1 \mathrm{ml}$ purified water (the vehicle used for HU). Group II (ginseng-treated) received $200 \mathrm{mg} / \mathrm{kg}$ b.wt of Panax ginseng extract (33). Group III (HUtreated) received hydroxyurea at a dose of 500 $\mathrm{mg} / \mathrm{kg}$ b.wt (34), HU solution was freshly prepared by tablets dissolving in purified water. Group IV (HU + ginseng) received hydroxyurea and ginseng extract in similar doses of group II and III. Twenty four hours after the last dose, the rats of each group were euthanized after light ether anesthesia to be subjected to the following studies.

\section{Hematological studies}

Anti-coagulated blood samples (in EDTA containing tubes) were collected from retro-orbital venous plexus for determination of erythrocytic (RBCs) count, and platelets count in addition to total and differential leukocytic count (Exigo ${ }^{\circledR}$ veterinary hematology system, Sweden) and for separation of plasma by samples centrifugation at $1000 \times \mathrm{g}$ for $10 \mathrm{~min}$.

\section{Biochemical analysis}

Plasma activities of AST, ALT and GGT, in addition to levels of urea and creatinine were determined using commercially available kits. Plasma level of IL-6 and TNF-alpha were detected by quantitative sandwich enzyme immunoassay method using Rat spicific ELISA kits (abcam, USA).

\section{Antioxidant studies}

About $1 \mathrm{~g}$ of kidney and liver of each euthanized animal were separated, perfuse with phosphate buffer saline solution (PBS) solution ( $\mathrm{pH}, 7.4$ ) containing $0.16 \mathrm{mg} / \mathrm{ml}$ heparin to remove any blood or clots, and homogenized in 9 ml PBS solution using tissue homogenizer (Glas-Col. Tissues homogenizer, China). Homogenate aliquots were centrifuged at 10,000 $\times$ $\mathrm{g}$ for $30 \mathrm{~min}$, supernatant were removed and stored at -80 till the time of assessment of concentration of malondialdehyde (MDA) and activity of glutathione peroxidase enzymes (GPX) using locally available kits (BiodiagnosticEgypt; Biovision, USA) and as previously described (35). Protein content was detected using Bradford's reagent (Sigma-Aldrich, USA).

\section{Histopathological examination}

Following necropsy specimens of livers and kidneys of each rat were collected and rapidly fixed for at least $24 \mathrm{~h}$ in $10 \%$ neutral buffered formalin. The fixed specimens were processed through the conventional paraffin embedding technique, sectioned at 5 microns and stained with Mayer's haematoxylin and eosin (H\&E). Stained sections were examined by light microscope and photographed using digital camera.

Semiquantitative histopathological scoring system

Semi quantitative histological scoring was carried out for the liver and kidneys slides. Five fields $(\times 100)$ were randomly selected from each rat in each group, and the most important pathological alterations were selected and scored in each organ; the severity of lesion was estimated according to the percentage of affected area/entire section where in: $0=$ absence of lesion, $1=$ $5-25 \%, 2=26-50 \%$, and $3=\geq 50 \%$

\section{Statistical analysis}

The statistical analysis was carried-out using one way analysis of variance (ANOVA) for studying of the effect of different treatment groups on different parameters studied using SAS, (2004) (36).

\section{Results}

\section{Hematological results}

As presented in Table 1, blood picture of HU-treated rats significantly showed a decrement in RBCs count which coupled by significant decrease in total leukocytic count (TLC), granulocytes, lymphocytes and monocytes 
counts in addition to platelets count when compared to control group. Unfortunately, co- administration of ginseng with HU failed to increase the diminished values of the previously listed parameters of blood picture as compared to HU-treated rats. The sole treatment with ginseng did not enhance any of these hematological parameters compared to control group.

\section{Biochemical changes}

As shown in Table 2, treatment of rats with HU evoked significant elevation in plasma activity of AST, ALT and GGT enzymes when compared to control group. Administration of ginseng with HDU significantly decreases plasma activity of these enzymes if compared to HU-treated animals. In the same manner, treatment with HU led to significant increase in plasma concentration of urea and creatinine which accompanied by significant decrease in plasma albumin concentration compared to control group. Comparatively with HU-treated group, co-administration of ginseng with $\mathrm{HU}$ significantly ameliorated the changes in these parameters. While, treatment with ginseng alone significantly decreased plasma activity of AST and ALT without any significant effect on the previously elucidated plasma hepato-renal function biomarkers compared to control group.

\section{Plasma level of inflammatory cytokines}

Plasma level of TNF-alpha and IL6 revealed a significant increase in HU-treated rats in comparison with control group. Meanwhile, their values were significantly diminished following co-administration of ginseng as compared to HU-treated animals. Moreover, administration of ginseng alone did not produce any alteration in plasma level of previously detected pro-inflammatory cytokines as compared to control group. (Table 2).

\section{Oxidative changes}

The level of MDA recorded a significant increase in hepatic and renal tissues of HUtreated rats which was accompanied by significant decline in GPX activity in these tissues when compared to control group. These elevations were significantly ameliorated toward normal control level upon co-treatment with ginseng. Treatment with ginseng alone did not reveal any significant changes in oxidant/antioxidant parameters in relation to control group (Table 3).

\section{Histopathological examination}

The histopathological changesdetected in livers and kidneys slides were represented in Figs. (1 and 2) and Table (4) which summarized the lesions' incidence and severity reported in $\mathrm{HU}$ and $\mathrm{HU}+$ Ginseng-treated groups. No histopathological alterations were detected in either control or Ginseng-treated rats groups.

\section{Liver}

Control (Fig.1A) and Ginseng-treated rats' livers showed normal histological structures. Meanwhile, livers of HU -treated rats showed diffuse hepatocytic cytoplasmic vacuolation of both fatty type (sharply outlined vacuoles, Fig.1B, Table4) and hydropic type (hazy border vacuoles). Widening of the hepatic sinusoids, hypertrophy of Kupffer cells, widespread moderate to severe congestion and multifocal areas of hemorrhages (Fig1C) were noticed. Furthermore, multifocal areas of hepatocellularnecrosis with mononuclear cells infiltrations were evident (Fig. 1D, Table 4). The Portal triads were thickened with edema and mononuclear cell infiltrations associated with atrophied hepatic cords (Fig1E, Table4). Conversely, livers of HU+ Ginseng- treated rats showed the previous described lesions but they were less in the severity and distribution (Fig.1F, Table4).

\section{Kidney}

Control (Fig.2A) and Ginseng-treated rat's kidneys exhibited normal histological limits of the glomeruli and renal parenchyma. HU treated rats showed degenerated tubular epithelium with star-shaped tubular lumen. Also, epithelium attenuation and necrosis with desquamated necrotic debris and inter tubular hyaline casts (Fig.2B, Table 4) were noticed. Regarding to the glomerular lesions, compressed capillary tufts with increased urinary spaces and presence of necrotic remnants of capillary tufts (Fig. 2C, Table 4) were recorded. Throughout the renal parenchyma, the interstitial tissue exhibited 
multifocal areas of interstitial nephritis with mononuclear cells infiltration, inter tubular edema and marked tubular dilatation (Fig. 2D). In addition, vascular congestion, moderate perivascular edema associated with lymphocytic cells infiltration and moderate fibroplasia (Fig.
2E, Table 4) were noticed. In contrast, the detected renal alternations in $\mathrm{HU}+$ Ginsengtreated group were reduced in the severity and distribution with marked improvement of the renal tissue (Fig. 2 F, Table 4) as compared to $\mathrm{HU}$-treated group.

Table 1: Effect of HU and its combination with Ginseng on blood picture of male Wistar albino rats.

\begin{tabular}{ccccc}
\hline Groups & Control & Ginseng & HU & HU+ginseng \\
\hline RBCs $\left(\times 10^{6} / \mu \mathrm{L}\right)$ & $7.86 \pm 0.27 \mathrm{a}$ & $7.85 \pm 0.27 \mathrm{a}$ & $5.40 \pm 0.19 \mathrm{~b}$ & $5.28 \pm 0.24 \mathrm{~b}$ \\
$\mathrm{TLC}\left(\times 10^{3} / \mu \mathrm{L}\right)$ & $14.12 \pm 0.23 \mathrm{a}$ & $14.96 \pm 0.28 \mathrm{a}$ & $8.56 \pm 0.26 \mathrm{~b}$ & $8.31 \pm 0.25 \mathrm{~b}$ \\
Granulocyt $\left(\times 10^{3} / \mu \mathrm{L}\right)$ & $4.18 \pm 0.26 \mathrm{a}$ & $4.59 \pm 0.13 \mathrm{a}$ & $1.82 \pm 0.05 \mathrm{~b}$ & $1.84 \pm 0.03 \mathrm{~b}$ \\
& & & & \\
Lymphocyte $\left(\times 10^{3} / \mu \mathrm{L}\right)$ & $8.46 \pm 0.21 \mathrm{a}$ & $8.76 \pm 0.23 \mathrm{a}$ & $5.78 \pm 0.27 \mathrm{~b}$ & $5.68 \pm 0.25 \mathrm{~b}$ \\
Monocyte $\left(\times 10^{3} / \mu \mathrm{L}\right)$ & $1.47 \pm 0.16 \mathrm{a}$ & $1.51 \pm 0.15 \mathrm{a}$ & $0.95 \pm 0.07 \mathrm{~b}$ & $0.93 \pm 0.06 \mathrm{~b}$ \\
Platelets $\left(\times 10^{3} / \mu \mathrm{L}\right)$ & $555.20 \pm 8.01 \mathrm{a}$ & $552.80 \pm 9.32 \mathrm{a}$ & $330.80 \pm 17.31 \mathrm{~b}$ & $329.00 \pm 17.42 \mathrm{~b}$
\end{tabular}

All values are expressed as mean \pm Std. Error. Means within the same raw of different litters are significantly different at $(\mathrm{P}<0.05)$. H: Hydroxyurea, Ginsing: Panax ginseng extract

Table 2: Effect of different treatments on different plasma hepatic and renal function biomarkers and plasma pro-inflammatory cytokins in male Wistar albino rats

\begin{tabular}{ccccc}
\hline Groups & Control & Ginseng & HU & HU+ginseng \\
\hline AST(U/L) & $51.40 \pm 2.60 \mathrm{~b}$ & $48.40 \pm 2.93 \mathrm{c}$ & $84.70 \pm 2.01 \mathrm{a}$ & $58.30 \pm 4.09 \mathrm{~b}$ \\
ALT(U/L) & $34.20 \pm 2.99 \mathrm{c}$ & $32.40 \pm 2.86 \mathrm{~d}$ & $72.60 \pm 5.18 \mathrm{a}$ & $47.60 \pm 2.96 \mathrm{~b}$ \\
GGT(U/L) & $31.00 \pm 3.30 \mathrm{c}$ & $31.20 \pm 2.29 \mathrm{c}$ & $57.00 \pm 2.57 \mathrm{a}$ & $39.90 \pm 2.90 \mathrm{~b}$ \\
Urea $(\mathrm{mg} / \mathrm{dl})$ & $54.20 \pm 2.51 \mathrm{~b}$ & $50.60 \pm 1.98 \mathrm{c}$ & $80.40 \pm 2.94 \mathrm{a}$ & $53.84 \pm 4.00 \mathrm{~b}$ \\
Creatinine(mg/dl) & $0.54 \pm 0.01 \mathrm{c}$ & $0.53 \pm 0.01 \mathrm{c}$ & $0.76 \pm 0.01 \mathrm{a}$ & $0.63 \pm 0.01 \mathrm{~b}$ \\
Albumin(g/dl) & $6.02 \pm 0.06 \mathrm{a}$ & $5.92 \pm 0.13 \mathrm{a}$ & $4.09 \pm 0.08 \mathrm{c}$ & $5.02 \pm 0.18 \mathrm{~b}$ \\
TNF(pg/ml) & $27.76 \pm 2.17 \mathrm{c}$ & $28.20 \pm 2.33 \mathrm{c}$ & $236.10 \pm 17.65 \mathrm{a}$ & $138.50 \pm 6.67 \mathrm{~b}$ \\
$\mathrm{IL} 6(\mathrm{pg} / \mathrm{ml})$ & $18.94 \pm 1.52 \mathrm{c}$ & $17.50 \pm 1.50 \mathrm{c}$ & $125.96 \pm 5.65 \mathrm{a}$ & $64.58 \pm 8.42 \mathrm{~b}$
\end{tabular}

All values are expressed as mean \pm Std. Error. Means within the same raw of different litters are significantly different at $(\mathrm{P}<0.05)$. 
Table 3: Effect of different treatments on hepatic and renal MDA and GPX in male Wistar albino rats

\begin{tabular}{ccccc}
\hline Groups & Control & Ginseng & HU & HU+ginseng \\
\hline $\begin{array}{c}\text { Liver MDA } \\
(\mu \mathrm{mol} / \mathrm{g} \text { protein })\end{array}$ & $8.98 \pm 0.93 \mathrm{c}$ & $7.59 \pm 0.53 \mathrm{c}$ & $26.96 \pm 1.44 \mathrm{a}$ & $26.96 \pm 1.44 \mathrm{a}$ \\
$\begin{array}{c}\text { Kidney MDA } \\
(\mu \mathrm{mol} / \mathrm{g} \text { protein })\end{array}$ & $5.03 \pm 0.87 \mathrm{c}$ & $4.31 \pm 0.74 \mathrm{c}$ & $22.46 \pm 2.06 \mathrm{a}$ & $13.57 \pm 0.92 \mathrm{~b}$ \\
$\begin{array}{c}\text { Liver GPX } \\
(\mathrm{U} / \mathrm{mg} \text {. protein })\end{array}$ & $3.28 \pm 0.29 \mathrm{a}$ & $3.66 \pm 0.37 \mathrm{a}$ & $1.81 \pm 0.12 \mathrm{~b}$ & $2.84 \pm 0.28 \mathrm{a}$ \\
$\begin{array}{c}\text { Kidney GPX } \\
(\mathrm{U} / \mathrm{mg} \text { protein }) .\end{array}$ & $3.04 \pm 0.42 \mathrm{ab}$ & $3.44 \pm 0.26 \mathrm{a}$ & $1.74 \pm 0.15 \mathrm{c}$ & $2.37 \pm 0.19 \mathrm{~b}$ \\
\hline
\end{tabular}

All values are expressed as mean \pm Std. Error. Means within the same raw of different litters are significantly different at $(\mathrm{P}<0.05)$.

\section{Discussion}

Hydrxyurea is a potent anti-neoplastic drug which is widely used to prevent painful crises of sickle cell anemia (37). Most available toxicity data from animals are present only in product labels, which are incomplete, and are often found only in summary statements (reviewed by Liebelt et al. 2007) (38). This study aimed to evaluate the toxic side effects of HU on liver and kidney tissues of rats and the probable role of Panax ginseng in refinement of such effects. $\mathrm{HU}$ is a small molecule, which is rapidly taken up by water and distributed widely throughout the body; it may reach vulnerable areas rapidly causing prompt cytotoxicity $(39,40)$.

Myelosupression is one of the major associated complications of the treatment with hydroxyurea (41), as HU can kill S-phase colonyforming unit (CFU) cells of bone marrow and retard the entry of surviving cells into S-phase of division (42) and this may explain the significant reduction in RBCs, leukocytic and platelets count of HU-treated group. Also, HU has the ability to induce damage to erythrocytes membranes due to erythrocytic membrane lipid peroxidation causing lysis of RBC (43) which can be considered as another illustration for the decrement of RBCs count. On the other hand, hydroxyurea inhibit DNA synthesis in germinal center of lymph follicle (44) which may explain the cause of lymphopenia in HU-treated animals. It was suggested that hydroxyurea can induce production of intracellular ROS (42-47) which are involved in cytotoxic effect of hydroxyurea $(48,49)$, as the mechanisms of action of HU depends on its rapid metabolism which produce carbomoylnitroso intermediate which then turned to nitroxide compounds (including nitric oxide) that are responsible for most of toxic effects of $\mathrm{HU}(50,51)$. These nitroxides act as free radicals which enhance formation of reactive oxygen species, creating oxidative stress state, interacting with nucleic acids and proteins to offset cellular functions, and altering cell signaling (51). This could be the reason for the elevated plasma activities of different liver enzymes (AST, ALT and GGT) due hepato cellular necrosis and membrane damage causes the release of these enzymes into the circulationin addition to increased plasma level of urea and creatinine. This Indicated oxidative hepato-nephrotoxic effect of HU which was affirmed by our histopathological findings. 

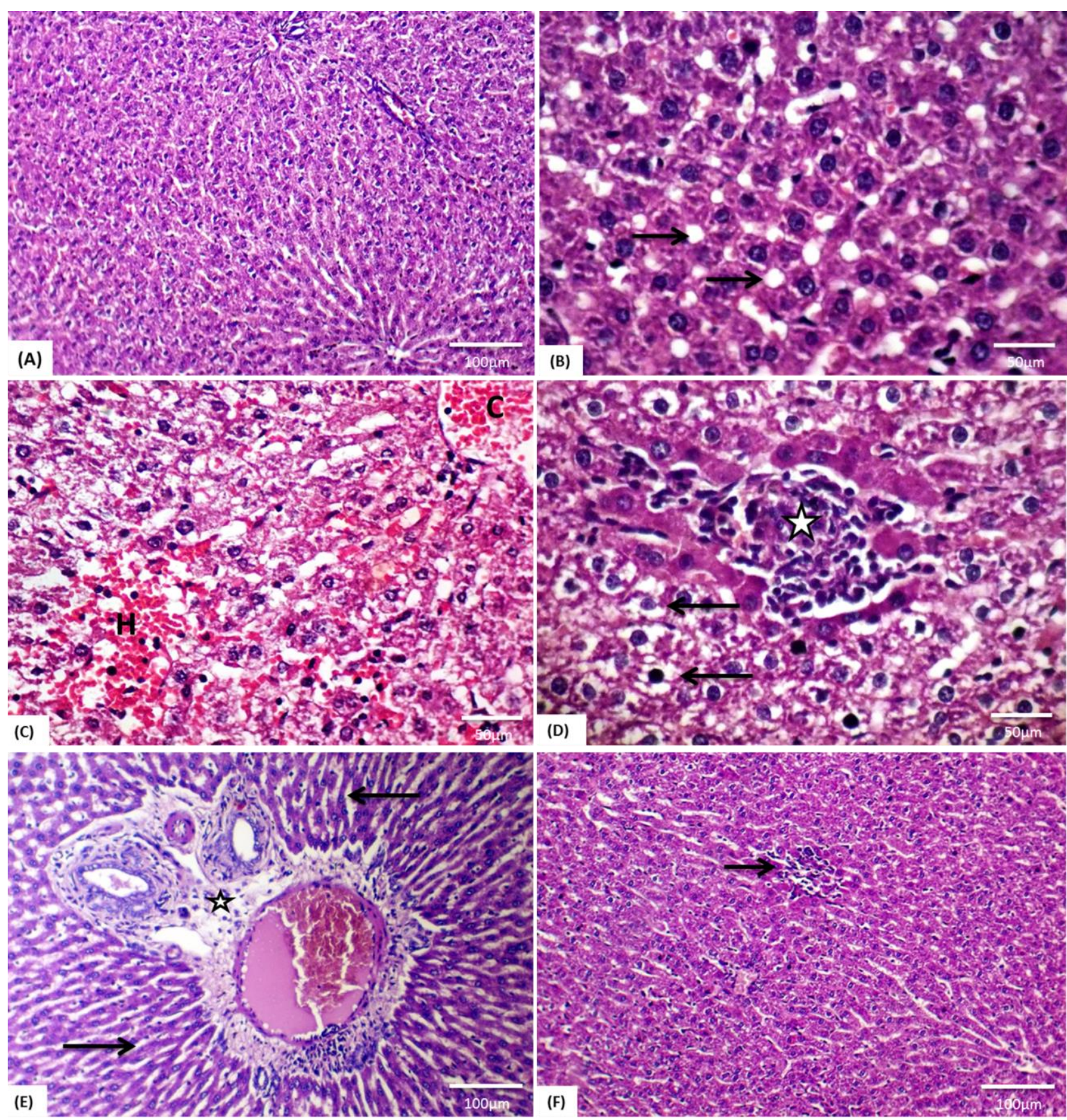

Figure 1: Representitive photomicrograph of rat livers stained with HE: (A) Normal histoarchitecture of a control rat liver (X100). (B,C,D\&E) livers of HD- treated rats: (B) Hepatocytes showing sharply outlined fat vacuoles (arrows, X400), (C) Replacement of the necrotic hepatocytes with RBCs and mononuclear cells $(\mathrm{H})$ associated with congestion (C, X400), (D) Hepatocyte cytoplasm showing hazy border vacuoles (arrows) in and hepatocellular necrosis with mononuclear cells infiltrations (asterisks, X400), (E) Thickening of the portal areas with edema and mononuclear cells infiltrations (asterisks) with newely formed bile ductules and atophied hepatic cords (arrows, X100). (F) HD+ Ginseng -treated rats showed markrd improvement of the hepatic tissue with minute area of hepatocellular necrosis ( arrow, X100) 


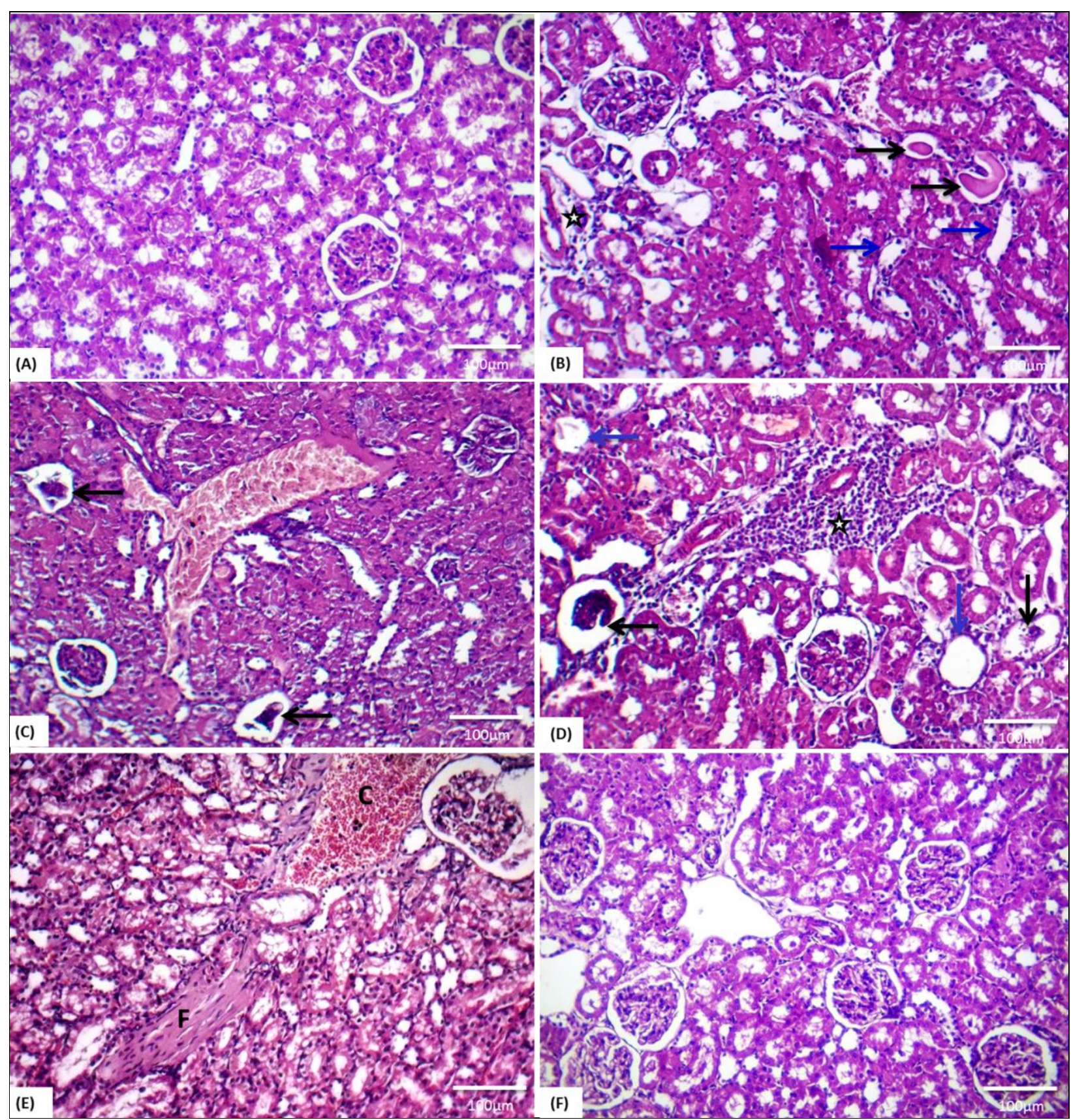

Figure 2: Representitive photomicrograph of rat kidneys stained with HE.X100: (A) Normal histoarchitecture of a control rat kidney. (B,C,D\&E) kidneys of HU- treated rats: (B) Entertubular hyaline casts (black arrows), thining and attinuation of the tubular epitheium (blue arrows) and perivascular lymphocytic cells infiltration (asterisk), (C) Necrotic capillary tufts with widening of urinary space (arrows) associated with vascular congestion,(D) Interstitial mononuclear cells infiltrations in the renal cortex ( asterisk) with atrophied and necrotic glomerular tufts (black arrows) cystically dilated renal tubules (blue arrows), (E) Vascular congestion(c) and fibroplasia of interstitial tissue (F). (F) HU + Ginseng -treated rats showing marked improvement of the renal tissue. 
Table 4: Incidence and Severityof histopathological lesions recorded in livers and kidneys tissyes of HU and HU+Ginseng- treated rats

\begin{tabular}{|c|c|c|c|c|c|c|c|c|}
\hline \multirow{3}{*}{ Scored lesions } & \multicolumn{8}{|c|}{ Incidence $^{1}$ and Severity ${ }^{2}$ of histopathological Lesions } \\
\hline & \multicolumn{4}{|c|}{ HU-treated rats } & \multicolumn{3}{|c|}{ HU+ Ginseng-treated rats } & \multirow[b]{2}{*}{$\begin{array}{l}\text { Severe } \\
(+++)\end{array}$} \\
\hline & $\begin{array}{c}\text { Ab- } \\
\text { sent } \\
(-)\end{array}$ & $\begin{array}{c}\text { Mild } \\
(+)\end{array}$ & $\begin{array}{l}\text { Moder- } \\
\text { ate } \\
(++)\end{array}$ & $\begin{array}{l}\text { Severe } \\
(+++)\end{array}$ & $\begin{array}{c}\text { Ab- } \\
\text { sent } \\
(-) \\
\end{array}$ & $\begin{array}{l}\text { Mild } \\
(+)\end{array}$ & $\begin{array}{c}\text { Moder- } \\
\text { ate } \\
(++)\end{array}$ & \\
\hline \multicolumn{9}{|c|}{ Liver } \\
\hline $\begin{array}{l}\text { a-Hepatocytic vac- } \\
\text { ular and hydropic } \\
\text { degeneration }\end{array}$ & 0 & 0 & 4 & 6 & 0 & 0 & 8 & 2 \\
\hline $\begin{array}{l}\text { b-Hepatocytic fat- } \\
\text { tyvaculation }\end{array}$ & 0 & 0 & 7 & 3 & 0 & 6 & 3 & 1 \\
\hline $\begin{array}{l}\text { c-Congestion of cen- } \\
\text { tral and portal veins. }\end{array}$ & 0 & 1 & 3 & 6 & 1 & 6 & 4 & 0 \\
\hline $\begin{array}{l}\text { d-Hepatocellular ne- } \\
\text { crosis. }\end{array}$ & 0 & 0 & 8 & 2 & 0 & 7 & 2 & 1 \\
\hline $\begin{array}{l}\text { e-Periportal infilama- } \\
\text { tory cells infiltra- } \\
\text { tions. }\end{array}$ & 0 & 0 & 6 & 4 & 0 & 5 & 3 & 2 \\
\hline \multicolumn{9}{|c|}{ Kidneys } \\
\hline $\begin{array}{l}\text { a-Inter tubular cast } \\
\text { formation }\end{array}$ & 0 & 1 & 6 & 3 & 0 & 6 & 3 & 1 \\
\hline $\begin{array}{l}\text { b-Tubular epitheium } \\
\text { necrosis }\end{array}$ & 0 & 0 & 3 & 7 & 0 & 7 & 2 & 1 \\
\hline $\begin{array}{l}\text { c-Vascular conges- } \\
\text { tion (cortical or me- } \\
\text { dullary) }\end{array}$ & 0 & 0 & 4 & 6 & 0 & 6 & 4 & 0 \\
\hline d-Glomerular lesions & 0 & 0 & 7 & 3 & 0 & 8 & 2 & 0 \\
\hline $\begin{array}{l}\text { e-Interstitial mononu- } \\
\text { clear cells infiltra- } \\
\text { tions }\end{array}$ & 0 & 0 & 8 & 2 & 0 & 6 & 4 & 0 \\
\hline f-Interstitial fibrosis & 0 & 0 & 6 & 4 & 3 & 5 & 2 & 0 \\
\hline
\end{tabular}

${ }^{1}$ Number of rats with lesions per total examined (10 rats).

${ }^{2}$ Severity of lesions was graded by estimating the percentage area affected in the entire section.

-Lesion scoring: $(0)$ absence of the lesion $=0 \%,(+)$ mild $=5-25 \%,(++)$ moderate $=26-50 \%$ and $(+++)$ severe $\geq 50 \%$ of the examined tissue sections. HU(hydroxyurea) and Ginsing(Panax ginseng extract ).

Plasma albumin level is considered as a good indicator for assessment of liver and kidney function as it synthesized by liver and reabsorbed by renal tubules after glomerular filtration, in addition, it is considered one of negative acute phase proteins as its level decreases in response to inflammation (52), so, its level decrement in HU-treated rats may be attributed to the pre-mentioned oxidative hepato-renal affection which could affect hepatic albumin production and increase urinary albumin loss or due to hepato-renal inflammatory state.
Oxidative damage of HU was proved in our study by increased level of MDA (lipid peroxide) and decreased level of GPX in both of hepatic and kidney tissues of HU-treated animals which accompanied by an elevated level of IL6 and TNF alpha in serum of the same animal group. Parallel to this, HU-induced hepato-nephrotoxic damages were affirmed histopathologically by presence of different hepatic and renal lesions that were previously mentioned in HU-treated rat group. Similar lesions were re- 
ported by Ahmad et al. (2018) (53). The detected hepato-renal structural distortion may be due to previously mentioned HU-induced oxidative damage. Fortunately, most of biochemical and histopathological alterations caused by HU administration were partially reversed upon co-administration with ginseng. The semiquantitative scoring system demonstrated the protective role of ginseng in HU treated- rats group which was displayed by decreasing the intensity and distribution of the recorded hepatorenal lesions. This effectuation may be attributed to antioxidant activity of Panax ginseng that was previously cleared in several studies (54-56). Hepato-renal protective effect of ginseng as an antioxidant was previously recorded in different studies (57-60).

\section{Conclusion}

Finally, we could conclude that hydroxyurea has an oxidative stress-related deleterious effect on liver and kidneys, in addition to blood cellular components, but, these effects can be partially ameliorated upon administration of ginseng extract as a dietary antioxidant.

\section{Conflict of interest}

The authors declare that they have no conflict of interest.

\section{References}

1. FDA. Center for Drug Evaluation and Research. Hydrea ${ }^{\circledR}$ packet insert.2010 http://www.accessdata.fda.gov/drugsatfda_docs/la-

bel/2010/016295s040lbl.pdf.

2. Marconato L, Bonfanti U, Fileccia I. Unusual dermatologic toxicity of hydroxyurea in two dogs with spontaneously occurring tumors. J Sm An Pract2007;48: 514-17.

3.Rassnick KM, Al-Sarraf R, Bailey DB, Chretin JD, Phillips B Zwhalen CH. Phase II openlabel study of single-agent hydroxyureafor treatment of mast cell tumours in dogs. Vet Comp Oncol 2010; 8: 103-11.

4. Bunn HF. Pathogenesis and treatment of sickle cell disease. N Eng J Med1997; 337: 762-69.

5.Charache S, Terrin ML, Moore RD, Dover GJ, Barton FB, Eckert SV, McMahon RP, Bonds DR. Effect of hydroxyurea on the frequency of painful crises in sickle cell anemia. N Eng J Med 1995; 332: 1317-22.
6. Venkayala SL, HargisJC, Woodcock HL.Unlockingthebinding and reaction mechanism of hydroxyurea substrates as biological nitric oxide donors. J Chem Info Modeling 2012; 52: 1288-97.

7.Silva-Pinto AC, Dias-Carlos C, SaldanhaAraujo F, Ferreira FIS, Palma PVB, Araujo AG et al. Hydroxycarbamide modulates components involved in the regulation of adenosine levels in blood cells from sickle-cell anemia patients. Ann Hematol 2014; 93:1457-65.

8. Philips FS, Sternberg SS, Schwartz HS, Cronin AP, Sodergren JE, Vidal PM. Hydroxyurea I. Acute cell death in proliferating tissues in rats.Cancer Res 1967; 27: 61-74.

9. Jiang J, Jordan SJ, Barr DP, Gunther MR, Maeda H, Mason RP. In vivo production of nitric oxide in rats after administration of hydroxyurea. MolPharmacol. 1997; 52(6):1081-6.

10. Jordan A., Reichard P. Ribonucleotide reductases. Annu. Rev. Biochem. 1998;67:71-98.

11. Shao J, Zhou B, Chu B, Yen Y. Ribonucleotide reductase inhibitors and future drug design. Curr Cancer Drug Targ 2006; 6:409-31.

12. Saban N, Bujak M. Hydroxyurea and hydroxamic acid derivatives as antitumor drugs. Cancer ChemotherPharmacol 2009; 64: 213-21.

13. FDA. Center for Drug Evaluation and Research. Droxia ${ }^{\circledR}$ packet insert. 2012 http://www.accessdata.fda.gov/drugsatfda_docs/label/2012/016295s041s042lbl.pdf.

14. Morton D, Reed L, Huang W, Marcek JM, Austin-LaFrance R, Northcott CA et al. Toxicity of Hydroxyurea in Rats and Dogs.ToxicolPathol 2015;43(4):498-512.

15.Saalu LC, Osinubi AA, Akinbami AA., YamaOE, Oyewopo AO, Enaibe BU. Moringaoleifera Lamarck (drumstick) Leaf Extract Modulates the Evidences of Hydroxyurea -Induced Testicular Derangement. Int J Appli Res Natur Products 2011; 4 (2): $32-45$.

16. Wray JD. Methaemoglobinaemia caused by hydroxycarbamide (hydroxyurea) ingestion in a dog. J Sm An Pract 2008;49: 211-15.

17. O'Branski EE, Ware RE, Prose NS, Kinney TR. Skin and nail changes in children with sickle cell anemia receiving hydroxyurea therapy. J Am AcadDermato2001; 144: 859-61.

18. Vassallo C, Passamonti F, AdrigoM,Nolli G, Mangiacavalli S, Boroni G. Muco-cutaneous changes during long-term therapy with hydroxyurea in chronic myeloid leukemia. ClinExpDermatol 2001; 26: 141-48. 
19. Imai H, MatsumuraN, YamazakiY, KanayamaY, MasudaT, KuwakoT, KamideY, TomizawaT, Matsumoto S, MitsuiT, KairaK, OnoA, KogaY, ShibusawaN, SunagaN, HisadaT, Yokoo H, Yamada M. Hydroxyurea-induced Pneumonitis in a Patient with Chronic Myelomonocytic Leukemia: An Autopsy Case. Int Med 2015; 54: 3171-76.

20. Bargagl IE, Palazz IM, Perri F, TorricelliE, Rosi E, BindiA, PistolesiM, Voltolini L. Fibrotic Lung Toxicity Induced by Hydroxycarbamide. In Vivo 2017; 31(6): 1221-23.

21. Kiefer D., Pantuso T. Panax ginseng. Am Fam Physician. 2003; 68: 1539-1542.

22. Cho I.H. Effects of Panax ginseng in neurodegenerative diseases. J Ginseng Res. 2012; 36 : 342-53.

23. Ernst E. Panax ginseng: an overview of the clinical evidence. J Ginseng Res. 2010; 34: 259-63.

24. Park HJ, Kim DH, Park SJ, Kim JM, Ryu JH. Ginseng in traditional herbal prescriptions. J Ginseng Res. 2012; 36:225-41.

25. Baek SH, Bae ON, Park JH. Recent methodology in ginseng analysis. J Ginseng Res. 2012; 36:119-34.

26. Choi KT. Botanical characteristics, pharmacological effects and medicinal components of Korean Panax ginseng CA Meyer. ActaPharmacol Sin. 2008; 29:1109-18.

27. Park SH, Oh MR, Choi EK, Kim MG, Ha KC, Lee SK, Kim YG, Park BH, Kim DS, Chae SW. An 8-wk, randomized, double-blind, placebo-controlled clinical trial for the antidiabetic effects of hydrolyzed ginseng extract. J Ginseng Res. 2014; 38(4):239-43.

28. Cha KM, Kopalli SR, Han SY, Lee SH, Jeong MS, Cho JY ha KM, Rajendra KS, Yun HS, Lee SH, Jeong MS, Cho J, Han CG, Lee SH, Kim SN, Kim JC, Kim SK. Korean red ginseng attenuates doxorubicin-induced testicular dysfunction in rats by modulating inflammatory, oxidative, and autophagy responses, J Funct Food 2018; 40:73643.

29. Kim SJ, Kim AK. Anti-breast cancer activity of fine black ginseng (Panax ginseng Meyer) and ginsenoside Rg5. J Ginseng Res 2015; 39(2):12534.

30.Chen G, Li H, Zhao Y, Zhu H, Cai E, GaoY,Liu S, Yang H1, Zhang L. Saponins from stems and leaves of Panax ginseng prevent obesity via regulating thermogenesis, lipogenesis and lipolysis in high-fat diet-induced obese C57BL/6 mice. Food ChemToxicol 2017; 106(A) 393-403.
31. Kang S, Min H. Ginseng, the 'Immunity Boost': the effects of Panax ginseng on immune system. J Ginseng Res 2012; 36:354-68.

32. Kim SJ, Kim AK. Anti-breast cancer activity of fine black ginseng (Panax ginseng Meyer) and ginsenoside Rg5, J. Ginseng Res 2015; 39(2):12534

33.Kalkan Y, Kapakin KA, Kara A, Atabay T, Karadeniz A, Simsek N, Karakus E, Can I, Yildirim S, Ozkanlar S, Sengul E. Protective effect of Panax ginseng against serum biochemical changes and apoptosis in kidney of rats treated with gentamicin sulphate. J MolHist 2012; 43(5):603-13.

34. Nair AB, Jacob S. A simple practice guide for dose conversion betweenanimals and human $\mathbf{J}$ Basic Clin Pharma 2016; 7: 27-31.

35. El-Bayomi K M, Saleh A A, Awad A, ElTarabany M S, El-Qaliouby H S, Afifi M, El-Komy S, Essawi W M, Almadaly E A, El-Magd M A. Association of CYP19A1 gene polymorphisms with anoestrus in water buffaloes, Reproduction, Fertility and Development 2018; 30(3): 487-97.

36. SAS. Statistical analysis system. SAS User's Guide, SAS incorpInst 2004.

37. Schecheter AN, Rodgers GP. Sickle cell anemia-basic researches reach the clinic. Eng J Med 1995; 332: 1372-74.

38.Liebelt EL, Balk SJ, Faber W, Fisher JW, Hughes CL, Lanzkron S M. et al. NTP-CERHR expert panel report on the reproductive and developmental toxicity of hydroxyurea. Birth Defects Res 2007; 80: 259-366.

39. Ahmad ME, Shadab GG, Azfer, MA. Effect of oxymetholone on SCE frequency in human lymphocyte chromosomes in vitro. Teratogen Carcinog Mutagen 2003; 1: 267-72.

40. Johnson C, Telen MJ. Adhesion Molecules And Hydroxyurea In The Pathophysiology Of Sickle Cell Disease. Haematologica 2008; 93: 48185.

41.Iyamu EW, Fasold H, Roa D, del Pilar Aguinaga M, Asakura T, Turner EA. Hydroxyurea-induced oxidative damage of normal and sickle cell hemoglobins in vitro: amelioration by radical scavengers. J Clinic Lab Anal.2001; 15: 1-7.

42.Vassort F, Winterholer M, FrindelE,Tubiana M. Kinetic Parameters of bone marrow stem cells Using in vivo Suicide by Tritiated Thymidine or by Hydroxyurea. Blood 1973; 41(6): 789-96.

43. Malec J, Przybyszewski MW, Grabarczyk M, Sitarska, E. Hydroxyurea has the capacity to induce damage to human erythrocytes which can be modified by radical scavengers. BiochemBiophys Res Commun1984; 120:566-73. 
44. Farber E, Baserga R. Differential Effects of Hydroxyurea on Survival of Proliferating Cells in Vivo.Cancer Res. 1969; 29(1):136-9.

45. Sakano k. Oikawa s. Hasegawa K. Kawanishi S. Hydroxyurea Induces Site-specific DNA Damage via Formation of Hydrogen Peroxide and Nitric Oxide. Jpn. J. Cancer Res. 2011; 92: 116674.

46. Nagai T, Tarumoto T, Miyoshi T, Ohmine K, Muroi K, Komatsu N, Sassa S, Ozawa K. Oxidative Stress is Involved in Hydroxyurea-induced Erythroid Differentiation. British J. of Haematol 2003; 121: 657-61.

47. Cokic VP, Smith RD, Beleslin-Cokic BB, Njoroge JM, Miller JL, Gladwin MT,Schechter AN. Hydroxyurea induces fetal hemoglobin by the nitric oxide-dependent activation of soluble guanylylcyclase. J clinic invest 2003; 111(2): 231-9.

48. Przybyszewski WM, Malec J. Protection against hydroxyurea-induced cytotoxic effects in L5178Y cells by free radical scavengers. Cancer Lett 1982;17: 223-8.

49. Grabarczyk M, Przybyszewski WM, Kwiatkowska J, SitarskaE,Malec J. Alteration in lysosome supravital staining as marker ofhydroxyureainduced cytotoxicity and its modification by radical scavengers in L5178Y cells in culture. Neoplasma 1983; 30:541-6.

50. Yarbro JW. Mechanisms of action of hydroxyurea. SeminOncol 1992; 19:1-10.

51. Koviac P. Hydroxyurea (therapeutics and mechanism): Metabolism, carbamoylnitroso, nitroxyl, radicals, cell signaling and clinical applications. Med Hypotheses 2011; 76: 24-31.

52. Latimer KS, Mahaffey EA, Prasse KW. Veterinary Laboratory Medicine, Clinical Pathology. 4th ed. Iwoa State Press. USA 2003.

53. Ahmad MF, Ansari MO, Jameel S, Wani AL, Parveen N, Siddique HR et al. Protective Role of
Nimbolide against Chemotherapeutic Drug Hydroxyurea Induced Genetic and Oxidative Damage in an Animal Model. Environ Toxicol Pharmacol 2018; 60: 91-9.

54. Choe WCS, Chung W, Lee SKW, Leung AWN, Cheng CHK, Yue KKM. Ginsenoside Re of Panax Ginseng possesses significant antioxidant and antihyperlipidemic efficiencies in streptozotocin-induced diabetic rats. Euro J Pharma 2006; 550: 173-9.

55. Swairess FAR. Effect of Ginseng Extract Supplementation on Renal Functions in Diabetic Rats. J of Agri Sci 2011; 3(2): 17-31.

56. El-Denshary ES, Al-Gahazali MA, Mannaa FA, Salem HA, Hassan NS, Abdel-Wahhab MA. Dietary honey and ginseng protect against carbon tetrachloride-induced hepato-nephrotoxicity in rats. Exp Toxicol Pathol 2012; 64(7-8): 753-60.

57. Zhu H, Long MH, Wu J, Wang MM, Li XY, Shen Het al. Ginseng alleviates cyclophosphamideinduced hepatotoxicity via reversing disordered homeostasis of glutathione and bile acid. Sci Rep. 2015; 5:17536.

58. Qi ZL, Wang Z, Li W, Hou JG, Liu Y, Li XDet al. Nephroprotective Effects of Anthocyanin from the Fruits of Panax ginseng (GFA) on Cisplatin-Induced Acute Kidney Injury in Mice. Phytother Res 2017; 31(9):1400-9.

59.Wang W, Wang S, Liu J, Cai E, Zhu H, He Zet al.Sesquiterpenoids from the root of Panax Ginseng protect $\mathrm{CCl} 4$-induced acute liver injury by anti-inflammatory and anti-oxidative capabilities in mice. Biomed Pharmacother2018; 102: 412-19.

60.Zhou YD, Hou JG, Liu W, Ren S, Wang YP, Zhang Ret al. 20(R)-ginsenoside Rg3, a rare saponin from red ginseng, ameliorates acetaminopheninduced hepatotoxicity by suppressing PI3K/AKT pathway-mediated inflammation and apoptosis. IntImmunopharmacol 2018; 59: 21-30. 